\title{
Quantitive Study on Some Aspect of Occipital Area in Domestic Cat (Felis catus)
}

\author{
Uddin $\mathrm{M}^{1}$, Hossain $\mathrm{ME}^{1}$, Islam $\mathrm{MS}^{2}$, Hossain $\mathrm{MB}^{3}$ and Islam $\mathrm{KN}^{1}$ \\ ${ }^{1}$ Department of Anatomy and Histology, ${ }^{2}$ Department of Pathology and Parasitology, ${ }^{3}$ Department of \\ Physiology, Biochemistry and Pharmacology ${ }^{2}$, Chittagong Veterinary and Animal Sciences \\ University, Khulshi, Chittagong-4202, Bangladesh
}

[Received: December 19, Accepted: December 28, 2013]

\begin{abstract}
This study was planned to investigate some aspects of the morphometric characteristics of the occipital bone and foramen megnum in domestic cat (Felis catus). Twenty adult domestic cat including 10 males and 10 female cats were euthanized using diazepam (@20 mg/kg) and their skulls were macerated to give morphometric parameters. Student t-test with level of significance set at 5\% (p < 0.05 ) was used to analyze the obtained values. The height of occipital triangle, width of occipital condyles, width of jugular process were significantly larger in male than female. The mean height and width of the foramen magnum were $1.32 \pm 0.09 \mathrm{~cm}$ and $1.35 \pm 0.08 \mathrm{~cm}$, respectively, while the foramen index was below 100 at $90.72 \pm 4.93$. Parameters for the foramen magnum index showed significant difference between both sexes at $\mathrm{p}<0.05$. The foramen magnum showed shape variations and there were multiple hypoglossal foramina in over $80 \%$ of the cats. The morphometric values of the occipital bone and foramen magnum and clinical anatomy of the occipital region of the domestic cats provide an important baseline for further research in this field and could help in the better diagnosis, classification, and treatment of diseases related to this region and serve as a future reference defining an anatomic range.
\end{abstract}

Key words: morphometry, occipital bone, domestic cat, foramen magnum

\section{INTRODUCTION}

The foramen magnum and the occipital bone have been the objects of scientific investigations because of their morphological variability and clinical importance $^{[1,2]}$. In humans and animals, anomalies of the foramen magnum and the occipital bone can lead to neurological signs ${ }^{[3,4]}$. The foramen magnum is a fundamental component in the complex interaction of bony, ligamentous, and muscular structures composing the craniovertebral junction ${ }^{[5]}$. Configuration and size of the foramen magnum play an important role in the pathophysiology of various disorders of the craniovertebral junction ${ }^{[5,6,7]}$. The foramen magnum is an important landmark of the base of skull and is of particular interest to many fields of medicine ${ }^{[8]}$. Irregularities in the shape of the foramen magnum constitute a crucial problem in veterinary medicine. An irregularly formed foramen magnum can cause plenty of clinical symptoms, for example, convulsions, ataxias, prolapse of the brain to the medullary canal and occipital dysplasia ${ }^{[9,10]}$. Variations of the shape of foramen magnum have got diagnostic, clinical and radiological importance ${ }^{[11]}$. The dimensions of foramen magnum have clinical importance because the vital structures that pass through it may suffer compression as in cases of foramen megnum achondroplasia ${ }^{[12]}$ and foramen magnum brain herniation ${ }^{[13,14]}$. In neurosurgical practice, the transcondylar approach is commonly used to access the lesions which are ventral to the brainstem and cervicomedullary junction. It was reported that understanding the bony anatomy of the condylar region is important for this approach ${ }^{[15]}$.Thus, a fundamental knowledge of normal anatomy of this region is important to the clinician for diagnosis and treatment. The aim of our study was to find out various measurements of the occipital bone and foramen magnum of cat. These results could help in the better diagnosis, classification, and treatment of diseases related to this region and serve as a future reference defining an anatomic range.

\section{MATERIALS AND METHODS}

A total of 20 adult native domestic cats (Felis catus) of both sexes, equal in number (2-3 years of age) were collected from local fish markets of Chittagong. The live animals were first selected during ante mortem examination based on parameters of apparent good health and no skeletal deformation. The animals were weighed with a standard bathroom scale and euthanized by injecting diazepam (20 $\mathrm{mg} / \mathrm{kg}$ ) in jugular vein. The heads were severed at the atlanto-occipital junction and processed in the Anatomy Laboratory of Chittagong Veterinary and Animal Sciences University using the hot water maceration techniques as described by Simoens et al. ${ }^{[16]}$ which briefly were:

- On the working day, frozen cats head were allowed to thaw.

- Skin and most of the muscles were separated and eyes were enucleated.

- Heads were heated to over $80^{\circ} \mathrm{C}$ for at least 1 hour in solution of polycaboxylate and anionic surfactant [detergent] and soap chips.

- Muscle of boiled heads was separated with the aid of forceps and scalpel in running water. 
- Further separation of muscles and ligaments from the skulls was done after left in detergent water at least 20-30 minutes.

- Separation of remaining muscles and ligaments from the skull was done after left in $1 \%$ sodium hypochlorite solution for at least 24 hours.

- After that, the skulls were left in the above solution, for 48-72 hours with solution, being changed at least twice and clean in running tap water.

- The skulls were then left to dry.

The following measurements were made as defined by Simoens et al. ${ }^{[16]}$ and Onar et al. ${ }^{[17]}$ (Fig. 1): major width of occipital condyles, the major width between the bases of the jugular processes, height of the occipital triangle length, major width of the foramen magnum and height of the foramen magnum. The foramen magnum index (height of the foramen magnum $\times 100$ /major width of the foramen magnum) was calculated ${ }^{[16,}{ }^{17]}$. The difference between those osteometric indices in the two sexes of cats was evaluated using Student t-test with level of significance set at $5 \%(\mathrm{p}<0.05)$

Table 1. Morphometric analysis of the occipital bone and foramen megnum of the cat of major width of jugular process in male was 3.70 $\mathrm{cm}$, in female, it was $3.44 \mathrm{~cm}$. The height of occipital triangle, width of occipital condyles, widths of jugular process were significantly larger in male than female. The height and width of the foramen magnum were $1.23 \pm 0.09 \mathrm{~cm}, 1.35 \pm 0.08 \mathrm{~cm}$ respectively, while the foramen index was below 100 at $90.72 \pm 4.93$ (Fig.1). The foramen magnum index was significant between both sexes at $p<0.05$. The occurrence of multiple hypoglossal foramina was observed in $80 \%$ of the cats in this study $(n=16)$. Side to side variation with respect to this feature was observed in this study with two hypoglossal foramina on the right side and a single one on the left in 55\% $(\mathrm{n}=11)$, while $50 \%(\mathrm{n}=10)$ were actually divided by a bony specule.

HOT $=$ Height of occipital triangle; HOW = Height of occipital without foramen megnum; $\mathrm{MOC}=$ Major width of occipital condyle; MJP = Major width of jugular process; HFM = Height of foramen magnum; WFM = Width of foramen magnum; FMI = foramen magnum index; Values presented as mean \pm SE for 20 cats (10 male and 10 female cats); *the values differed significantly between the two sexes at $\mathrm{p}<0.05$.

\begin{tabular}{|c|c|c|c|c|}
\hline Measurements & Overall mean & Male & Female & $\mathrm{P}$ value \\
\hline $\mathrm{HOT}^{*}[\mathrm{~cm}]$ & $2.42 \pm 0.11$ & $2.48 \pm 0.09$ & $2.37 \pm 0.10$ & 0.0171 \\
\hline $\mathrm{HOW} *[\mathrm{~cm}]$ & $1.725 \pm 0.25$ & $1.83 \pm 0.24$ & $1.62 \pm 0.23$ & 0.0567 \\
\hline $\mathrm{MOC}^{*}[\mathrm{~cm}]$ & $2.08 \pm 0.19$ & $2.16 \pm 0.20$ & $1.99 \pm 0.15$ & 0.0446 \\
\hline $\mathrm{MJP}^{*}[\mathrm{~cm}]$ & $3.57 \pm 0.28$ & $3.70 \pm 0.29$ & $3.44 \pm 0.20$ & 0.0320 \\
\hline $\mathrm{HFM}[\mathrm{cm}]$ & $1.23 \pm 0.09$ & $1.19 \pm 0.08$ & $1.27 \pm 0.09$ & 1.0201 \\
\hline $\mathrm{WFM}[\mathrm{cm}]$ & $1.35 \pm 0.08$ & $1.37 \pm 0.09$ & $1.33 \pm 0.06$ & 0.9503 \\
\hline FMI*[\%] & $90.72 \pm 4.93$ & $86.98 \pm 2.78$ & $94.42 \pm 3.52$ & 0.0006 \\
\hline
\end{tabular}

\section{RESULTS}

Analysis of the dentition and skull sutures proved that all investigated domestic cats were adults. The occipital bone was well developed and its morphology was characteristic for cats.

There were significant differences in the measurements of the occipital bone between investigated males and females. The foramen magnum in all cats was typical in shape, without dorsal notch occurrence. The value of the osteometric data of the occipital bone and foramen magnum, as well as mean values and Standard deviations, are given in Table 1 . The mean value of occipital triangle in male was $2.48 \mathrm{~cm}$, in female, it was $2.37 \mathrm{~cm}$. Height of occipital bone without foramen magnum in males and females were $1.83 \mathrm{~cm}$ and $1.62 \mathrm{~cm}$, respectively. The mean value of major width of occipital condyle in males and females were $2.16 \mathrm{~cm}$ and $1.99 \mathrm{~cm}$, respectively. The mean value
The normal build of the occipital bone and foramen magnum plays a significant role in correct cerebrospinal fluid (CSF) circulation. The obstruction of cerebrospinal fluid can result in the development of syringomyelia, fluid-containing cavities that develop in the spinal cord. In veterinary medicine, the most common cause of syringomyelia is occipital bone hypoplasia ${ }^{[18]}$. A dorsal notch (occipital dysplasia) was not observed in any investigated skull of cat. However, occipital dysplasia was observed in some dogs ${ }^{[17,19]}$ and African giant rat ${ }^{[20]}$ which may be physiologic ${ }^{[19]}$ or pathologic ${ }^{[4]}$ in animal. The height of occipital triangle, width of occipital condyles, width of jugular process were significantly larger in male than female which indicate the skull of male was larger than female cat. Comparatively, the skull of cat was larger than African rat ${ }^{[20]}$, rabbit ${ }^{[21]}$ and smaller than $\operatorname{dog}^{[17,19]}$. Variability of skull shape and size related to species. 
The mean foramen magnum width and height were $1.35 \mathrm{~cm}$ and $1.23 \mathrm{~cm}$, respectively. Comparatively, these values in domestic cats were higher than rabbit ${ }^{[21]}$, mole rat ${ }^{[22]}$ and African giant rat ${ }^{[20]}$ but lower than $\operatorname{dog}{ }^{[23]}$. The foramen magnum index of the domestic cat was 90.72 which was almost similar to that of the mole rat ${ }^{[22]}$ and perkingese $\operatorname{dog}{ }^{[24]}$ and higher than the rabbit ${ }^{[21]}$ and African giant rat ${ }^{[20]}$, where the foramen magna were relatively wide. However, the foramen magnum index was relatively higher in the West African Dwarf goat ${ }^{[25]}$ and American Staffordshire terrier newborns ${ }^{[26]}$. These above analysis proved that the foramen magnum had large size variability and was related to animal age and species. The foramen magnum width was significantly greater in the male than in the female in our study, although it is speculative whether this translates to the morphometry of the contained spinal cord and meninges. Various authors have stated that irregularities in the shape of the foramen magnum constitute a crucial problem in Veterinary Medicine and can cause a variety of clinical symptoms, for example, convulsions, ataxias, prolapse of the brain to the medullary canal, and occipital dysplasia ${ }^{[27,28]}$. However, Janeczek et al. ${ }^{[23]}$ considered it an ancient characteristic which is compatible with longevity and the absence of major pathology. However, this occurrence needs be verified to ascertain its effect in the domestic cat.

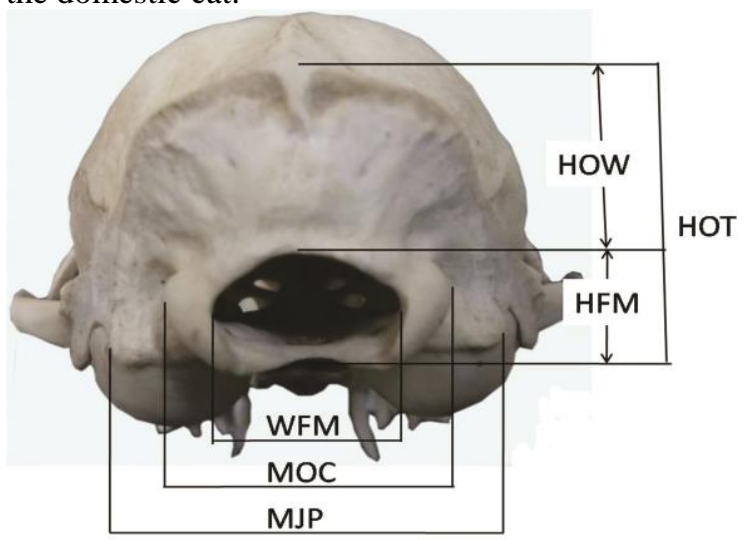

Figure 1. Morphometric measurements of occipital bone and foramen megnum: HOT $=$ Height of occipital triangle; HOW $=$ Height of occipital without foramen megnum; MOC = Major width of occipital condyle; MJP = Major width of jugular process; HFM = Height of foramen magnum; WFM $=$ Width of foramen magnum

A recent study on humans and other mammalian species ${ }^{[29]}$ revealed double hypoglossal canals in $43 \%$ of cases. In the same study, $28.12 \%$ of cases had the hypoglossal canal divided in two by a small bony spicule. The doubling of the hypoglossal canal by a bony spicule is not a rare phenomenon ${ }^{[30]}$. Fifty percent of the cats in this study had the canal divided by a bony spicule. The clinical significance of this has been attached to the variations in the hypoglossal foramen in humans, and knowledge of this anatomical variation could be important for various fields of medicine ${ }^{[31,32]}$.

\section{CONCLUSION}

The morphometric values of the occipital bone and foramen magnum and clinical anatomy of the occipital region of the domestic cats provide an important baseline for further research in this field. Furthermore, these results could help in the better diagnosis, classification, and treatment of diseases related to this region and serve as a future reference defining an anatomic range.

\section{ACKNOWLEDGEMENTS}

We greatly acknowledge the financial support provided by the Department of Anatomy and Histology of Chittagong Veterinary and Animal Sciences University, Bangladesh. We are also thankful to Dr. Mohammd Sarkar of our faculty of CVASU for his support and inspiration during the research tenure.

\section{REFERENCES}

1. Baranowski P, Wroblewska $\mathbf{M}$ and Wojtas $\mathbf{J}$ (2009). Morphology and morphometry of the nuchal plane of breeding chinchilla (Chinchilla laniger, Molina, 1782) skulls allowing for sex and litter size at birth. Bull. Vet. Puławy. 53: 291-298.

2. Miramontes Sequeiros LC, Palanca Castan N and Palanca Soler A (2010). Development of a new anatomical tool for the study of the occipital region in Delphinus delphis. Mar. Mammal. Sci. 26: 982-989.

3. Parker AJ and Park RD (1974). Unusual deformity of the occipital bone in a dog (case report). Vet. Med. Small Anim. Clin. 69: 440441.

4. Rusbridge C, Knowler SP, Pietrese L and McFayden AK (2009). Chiari-like malformation in the Griff on Bruxellois. J. Small Anim. Pract. 50: 386-393.

5. Bagley CA, Pindrik JA, Bookland MJ, CamaraQuintana JQ and Carson BS (2006). Cervicomedullary decompression for foramen magnum stenosis in achondroplasia. $J$. Neurosurg. 104:166-72.

6. Dickman C, Spetzler RF and Sonntag VK (1998). Surgery of the craniovertebral junction. 1st ed. New York: Thieme Medical Publishers.

7. Wang H, Rosenbaum AE, Reid CS, Zinreich SJ and Pyeritz RE (1987). Pediatric patients with achondroplasia: CT evaluation of the craniocervical junction. Radiol. 164:515-9.

8. Gruber P, Henneberg M, Boni T and Ruhli FJ (2009). Variability of human foramen magnum size. Anat. Rec. 292:1713-1719. 
9. Fayolle P, Autefage A and Genevois JP (1982). La dysplasia occipitale du chien. $R e^{\prime} v . M e^{\prime} d$. Vet. 133: 19-30.

10. Jensen BL and Kreiborg S (1993). Development of the skull in infants with cleidocranial dysplasia. J. Craniofacial Genet. Dev. Biol. 13: 89-97.

11. Murshed KA, Cicekcibasi AE and Tuncer I (2003). Morphometric evaluation of the foramen magnum and variations in its shape. A study on computerized tomographic images of normal adults. Turk. J. Med. Sci. 33:301-306.

12. Hecht JT, Horton WA, Reid CS, Pyeritz RE and Chakraborty R (1989). Growth of the foramen magnum in achondroplasia. Am. J. Med. Genet. 32:528-535.

13. Reich JB, Sierra J, Camp W, Zanzonico P, Deck MD and Plum F (1993). Magnetic resonance imaging measurements and clinical changes accompanying transtentorial and foramen magnum brain herniation. Ann. Neurol. 33:159170.

14. Ropper AH (1993). MRI demonstration of the major features of herniation. J. Neurol. Neurosurg. Psychiatry. 56:932-935.

15. Muthukumar N, Swaminathan R, Venkatesh G and Bhanumathy SP (2005). A morphometric analysis of the foramen magnum region as it relates to the transcondylar approach. Acta. Neurochir. 147:889-895.

16. Simoens R, Poles R and Lauwers H (1994). Morphometric analysis of foramen magnum in pekingese dogs. Am. J. Vet. Res. 55: 33-39.

17. Onar V, Mutus R and Kahvecioglu KO (1997). Morphometric analysis of the foramen magnum in German Shepherd dogs [Alsatians]. Ann. Anat. 179: 563-568.

18. Rusbridge C and Knowler SP (2006). Coexistence of occipital dysplasia and occipital hypoplasia/syringomyelia in the cavalier King Charles spaniel. J. Small Anim. Pract. 47: 603606.

19. Wright JA (1979). A study of the radiographic anatomy of the foramen magnum in dogs. $J$. Small Anim. Pract. 20: 501-508.

20. Olude MA, Olopade JO, Fatola IO and Onwuka SK (2009). Some aspects of the neurocraniometry of the African giant rat (Cricetomys gambianus Waterhouse). Fol. Morph. 68: 224-227.

21. Kahvecioghu KO, Onar V, Alpak H and Pazvant $\mathrm{G}$ (2000). The morphometry of the foramen magnum in rabbits and its correlation with craniometric measurements. Fol. Vet. 44: 62-69.

22. Özkan ZE (2007). Macro-anatomical investigations on the forelimb skeleton of molerat (Spalax leucodon Nordmann). Vet. Arh. 72: 91-99.

23. Janeczek M, Chroszcz A, Onar V, Pazvant G and Pospieszny N (2008). Morphological Analysis of the Foramen Magnum of Dogs from the Iron Age. Anat. Histo. Embryo. 37: 359-361.

24. Janeczek M and Aleksander C (2011). The occipital area in medieval dogs and the role of occipital dysplasia in dog breeding. Tur. J. Vet. Ani. Sci. 35: 453-458.

25. Olopade JO and Onwuka SK (2005). Some aspects of the Clinical Anatomy of the mandibular and maxillofacial regions of the West African Dwarf Goat in Nigeria. Int. J. Morph. 23: 33-36.

26. Chroszcz A, Janeczek $M$, Wojnar $M$ and Pospieszny N (2006). Morphological analysis and morphometry of the foramen magnum of the American Staffordshire terrier breed newborns. Med. Weteryn. 62: 1002-1004.

27. Van Herpen H and Voorhout G (1993). Occipital dysplasia in a Pomeranian dog. Tij Diergen . 118: 327-328.

28. Jensen BL and Kreiborg S (1993). Development of the skull in infants with cleidocranial dysplasia. J. Cranio. Gen. Develop. Biol. 13: 8997.

29. Wysocki J, Kobryn H, Bubrowski M, Kwiatkowski J, Reymond J and Skarzynska B (2004). The morphology of the hypoglossal canal and its size in relation to skull capacity in man and other mammal species. Fol. Morph. 63: 11-17.

30. Bhuller A, Sanudo JR, Choi D and Abrahams PH (1998). Intracranial course and relations of the hypoglossal nerve. An anatomic study. Surg. Radiol. Ana. 20: 109-112.

31. Bergman RA, Afifi AK and Miyauchi R (1988). Compendium of human anatomical variations. Urban and Schwarzenberg Baltimore.

32. Nayak SB (2008). Unilateral, double hypoglossal nerves leaving the cranial cavity through two hypoglossal foramina. a case report. Neuro. Anat. 7: 6-7. 